\title{
Dipyridamole magnetic resonance imaging: a comparison with thallium-201 emission tomography
}

\author{
D J Pennell, S R Underwood, P J Ell, R H Swanton, J M Walker, D B Longmore
}

\begin{abstract}
Limitation of space and motion artefact make magnetic resonance imaging during dynamic exercise difficult. Pharmacological stress with dipyridamole can be used as an alternative to exercise for thallium scanning. Forty patients with a history of angina and an abnormal exer-

with dipyridamole and may be associated with a reduced magnetic resonance signal. The failure to show wall motion abnormalities in all cases of reversible thallium defects may be because the defect was small or because dipyridamole caused perfusion defects in the absence of myocardial ischaemia.
\end{abstract} cise electrocardiogram were studied by dipyridamole thallium myocardial perfusion tomography and dipyridamole magnetic resonance wall motion imaging with a cine gradient refocused sequence. Images for both scans were obtained in the oblique horizontal and vertical long axis and short axis planes before and after pharmacological stress with dipyridamole. The myocardium was divided into nine segments for direct comparison of perfusion with wall motion. Segments were assessed visually into grades-normal, hypokinesis or reduced perfusion, and akinesis or very reduced perfusion. After dipyridamole there were reversible wall motion abnormalities in $24(62 \%)$ of 39 patients with coronary artery disease and $24(67 \%)$ of 36 patients with reversible thallium defects. The site of wall motion deterioration was always the site of a reversible thallium defect. Thallium defects affecting more than two segments were always associated with wall motion deterioration but most single segment thallium defects were undetected by magnetic resonance imaging. There was a significant correlation between detection of wall motion abnormality, the angiographic severity of coronary artery disease, and the induction of chest pain by dipyridamole. There were no significant differences in ventricular volume or ejection fraction changes after dipyridamole between the groups with and without detectable reversible wall motion changes but the normalised magnetic resonance signal intensity of the abnormally moving segments was significantly less than the signal intensity of the normal segments. In nine patients the change was apparent visually and it was maximal in the subendocardial region.

Magnetic resonance imaging of reversible wall motion abnormalities in patients with coronary artery disease is feasible during pharmacological stress
Magnetic resonance imaging of the cardiovascular system yields both anatomical and functional information with clarity and accuracy, but its application in patients with coronary artery disease has been limited by the difficulty of imaging during dynamic exercise. $^{1}$ Pharmacological intervention with dipyridamole offers a potential solution, and its use in combination with thallium-201 scintigraphy is well established as a method of assessing the impairment of myocardial perfusion in territories served by diseased coronary arteries. ${ }^{2}$ Echocardiography ${ }^{3}$ and radionuclide ventriculography ${ }^{4}$ showed that the inequalities of perfusion induced by dipyridamole may be sufficient to produce myocardial ischaemia and regional wall motion abnormalities, though the reported incidence of such changes is variable. ${ }^{56} \mathrm{We}$ therefore wanted to establish the feasibility of magnetic resonance imaging after intravenous dipyridamole and to investigate the relation between inequalities of myocardial perfusion shown by thallium-201 emission tomography and wall motion abnormalities shown by cine magnetic resonance imaging.

\section{Patients and methods}

We studied 40 patients (33 men and seven women aged 35-75 (mean 54)) with a history of chest pain and an abnormal exercise electrocardiogram. Twenty three patients had had a previous myocardial infarction. Magnetic resonance imaging and thallium-201 myocardial perfusion imaging were performed in all patients in the two days before coronary arteriography and there were no significant clinical events in the period between imaging and arteriography. Nine patients had three vessel disease, 21 two vessel disease, nine one vessel disease, and one patient had normal coronary arteries. Angina medication was stopped at least 12 hours before each study as was consumption of beverages containing caffeine (tea, coffee, cocoa). None of the patients had a history of bronchospasm and 
none was taking aminophylline or related drugs. Each patient gave informed consent and the study was approved by the hospital ethics committee.

MAGNETIC RESONANCE IMAGING

Cine magnetic resonance imaging was performed with a Picker International MR2055 scanner operating at $0.5 \mathrm{~T}$. Blood pressure was monitored by an automatic pneumatic cuff system and intravenous access was established through an indwelling cannula connected to fine bore tubing. The electrocardiogram was recorded in the normal way with lead CM5. We used a field even echo rephasing (FEER) sequence for cine imaging ${ }^{7}$ in the vertical long axis, horizontal long axis, and apical and basal short axis planes. The echo time of the sequence was $14 \mathrm{~ms}$ and the repetition time was adjusted to acquire 16 images spanning all but the final $60 \mathrm{~ms}$ of diastole. The field of view was $45 \mathrm{~cm}$, slice thickness was $10 \mathrm{~mm}$, and two acquisitions of 128 phase encoding steps were averaged. The images were interpolated from $128 \times 256$ pixels to $512 \times 512$ for display.

After acquisition of the initial images and without removing the patient from the magnet, dipyridamole was infused at a rate of $0.142 \mathrm{mg} / \mathrm{kg} / \mathrm{minute}$ for four minutes. In the absence of significant symptoms or a fall in mean blood pressure of more than $20 \mathrm{~mm} \mathrm{Hg}$, a further $10 \mathrm{mg}$ bolus was given at 10 minutes to maintain effects on wall motion. At the end of the infusion cine imaging was repeated in the same planes as before the infusion. The scanning time before dipyridamole was given was approximately 30 minutes including pilot images but after dipyridamole was given

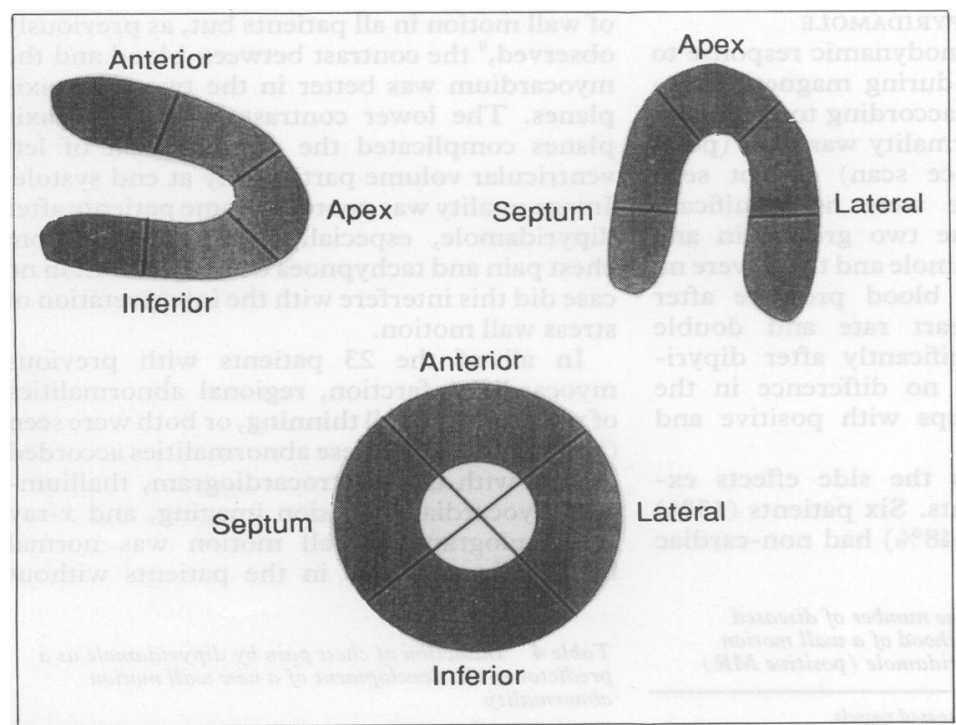

Figure 1 Diagram showing oblique imaging planes through the left ventricle. Vertical long axis (top left), horizontal long axis (top right), and short axis (bottom). The four walls were divided into apical and basal segments which with the apex produced a total of nine segments for analysis. Short axis images were acquired through the apical and basal parts of the ventricle so that each segment was seen independently in two different planes. scanning time was shorter because of the increase in heart rate, and it was typically 1520 minutes.

\section{THALLIUM-201 MYOCARDIAL PERFUSION IMAGING}

Dipyridamole was infused intravenously at a rate of $0.142 \mathrm{mg} / \mathrm{kg} / \mathrm{minute}$ for four minutes followed by $80 \mathrm{MBq}$ of thallium-201 four minutes from the end of the infusion. Emission tomographic imaging was started four minutes later with a General Electric 400AZS gamma camera and a General Electric Star computer system. Thirty two planar images $(64 \times 64$ pixel matrix, $400 \mathrm{~mm}$ field of view, $30 \mathrm{~s}$ per image) were acquired over a $180^{\circ}$ arc from the right anterior oblique position to the left posterior oblique position. Redistribution images were acquired after four hours in an identical manner. The planar images were reconstructed into transaxial tomograms of one pixel depth by back projection and a Ramp-Hanning filter with a $0.75 /$ pixel cut off frequency. From the transaxial tomograms, oblique images were reconstructed in the vertical long axis, horizontal long axis, and short axis planes.

\section{CORONARY ARTERIOGRAPHY}

Judkins's technique was used with multiple views of each vessel, and contrast left ventriculography was performed in the right anterior oblique projection.

\section{IMAGE ANALYSIS}

All images were assessed independently by two experienced observers without knowledge of the results of other investigations. Disagreements were resolved by discussion. The tomograms were divided as shown in fig 1 . Wall motion in each segment on the cine magnetic resonance tomograms was classed as normal, hypokinetic, or akinetic and myocardial perfusion was classed on the thallium-201 tomograms as normal, reduced, or absent. Because each segment of the myocardium was seen in two different planes, a total of nine segments was assessed and if the appearance of a segment differed between planes, the worse of the two classifications was used. A wall motion abnormality induced by dipyridamole was defined as a deterioration of at least one category and this finding was called a positive magnetic resonance scan. Dipyridamole induced ischaemia was defined as impaired perfusion with redistribution of at least one category in the delayed thallium-201 images. A significant coronary stenosis was defined as a reduction of at least $50 \%$ of the normal luminal diameter. Left ventricular end diastolic and end systolic volumes were calculated from the vertical and horizontal magnetic resonance tomograms by a biplane arealength technique. ${ }^{8}$ Stroke volume and ejection fraction were derived.

\section{STATISTICAL ANALYSIS}

Myocardial magnetic resonance signal levels and haemodynamic and ventricular volume differences before and after dipyridamole 
Table 1 Haemodynamic changes before and after intravenous dipyridamole given during magnetic resonance imaging

\begin{tabular}{|c|c|c|c|c|}
\hline & Before & After & Change (CI) & $p$ \\
\hline $\begin{array}{l}\text { Systolic BP }(\mathrm{mm} \mathrm{Hg}) \\
\text { Diastolic BP }(\mathrm{mm} \mathrm{Hg}) \\
\text { Heart rate }(\text { beats } / \mathrm{min}) \\
\text { Rate } \times \text { pressure }(\mathrm{mm} \mathrm{Hg} / \mathrm{min})\end{array}$ & $\begin{array}{r}134 \\
79 \\
67 \\
8955\end{array}$ & $\begin{array}{r}133 \\
76 \\
85 \\
11240\end{array}$ & $\begin{array}{rc}-1 & (-6,+3) \\
-3 & (-6,0) \\
18 & (+13,+23) \\
2285 & (+1544,+3344)\end{array}$ & $\begin{array}{l}\text { NS } \\
\text { NS } \\
<0.001 \\
<0.001\end{array}$ \\
\hline $\begin{array}{l}\text { Negative scan }(\mathrm{n}=16): \\
\text { Systolic BP }(\mathrm{mm} \mathrm{Hg}) \\
\text { Diastolic BP }(\mathrm{mm} \mathrm{Hg}) \\
\text { Heart rate }(\text { beats } / \mathrm{min}) \\
\text { Rate } \times \text { pressure }(\mathrm{mm} \mathrm{Hg} / \mathrm{min})\end{array}$ & $\begin{array}{r}131 \\
77 \\
61 \\
8047\end{array}$ & $\begin{array}{r}136 \\
75 \\
77 \\
10402\end{array}$ & $\begin{array}{rc}5 & (-5,+14) \\
-2 & (-6,+3) \\
16 & (+12,+19) \\
2355 & (+1418,+3356)\end{array}$ & $\begin{array}{l}\text { NS } \\
\text { NS } \\
<0.001 \\
<0.001\end{array}$ \\
\hline
\end{tabular}

Mean values are given in each group and the mean changes with $95 \%$ confidence interval (CI).

BP, blood pressure.

Table 2 Side effects and clinical observations after intravenous dipyridamole in 40 patients

\begin{tabular}{llc}
\hline Side effect & Number & $(\%)$ \\
\hline Chest pain & 27 & 68 \\
Headache & 12 & 30 \\
Facial flushing & 6 & 15 \\
Dyspnoea & 4 & 10 \\
Nausea & 3 & 8 \\
Arrhythmia & $3^{\star}$ & 8 \\
Tiredness & 2 & 5 \\
Perineal flushing & 1 & 3 \\
Felt unwell & 1 & 3 \\
Legs numb & 1 & 3 \\
\hline
\end{tabular}

$\star$ Ventricular extrasystoles 1 ; atrial extrasystoles 1 ; bigeminy 1 .

were compared by Student's paired $t$ test, with a logarithmic transformation for the double product data to achieve a normal distribution. Differences between groups were compared by a test of covariance. The $\chi^{2}$ test was also used where appropriate. A probability $<0.05$ was considered significant.

\section{Results}

CLINICAL EFFECTS OF DIPYRIDAMOLE

Table 1 shows the haemodynamic response to dipyridamole infusion during magnetic resonance imaging divided according to whether a new wall motion abnormality was seen (positive magnetic resonance scan) or not seen (negative scan). There were no significant differences between the two groups in any variable before dipyridamole and there were no significant changes in blood pressure after dipyridamole. The heart rate and double product increased significantly after dipyridamole but there was no difference in the response between groups with positive and negative scans.

Table 2 summarises the side effects experienced by the patients. Six patients $(15 \%)$ had no symptoms, $19(48 \%)$ had non-cardiac

Table 3 Relation between the number of diseased coronary vessels and the likelihood of a wall motion abnormality induced by dipyridamole (positive MR)

\begin{tabular}{lllrl}
\hline & \multicolumn{4}{l}{ No of diseased vessels } \\
\cline { 2 - 5 } & 0 & 1 & 2 & 3 \\
\hline Negative MR & 1 & 7 & 8 & 0 \\
Positive MR & 0 & 2 & 13 & 9 \\
\hline$\chi^{2}=12 \cdot 9 ; p$ & 0.01 & & &
\end{tabular}

side effects, and $27(68 \%)$ had cardiac side effects, the commonest of which was chest pain which occurred in all 27 patients $(68 \%)$ sometimes with dyspnoea. In none of these was the chest pain severe and only one patient was given aminophylline because of nausea. The chest pain occurred between one and four minutes after the end of the dipyridamole injection and persisted for up to 10 minutes. When a further $10 \mathrm{mg}$ bolus of dipyridamole was given at 10 minutes, this invariably worsened the discomfort. Arrhythmias occurred in only three $(8 \%)$ patients and they were unsustained and of no haemodynamic importance. Two of these patients had two vessel coronary disease with reversible ischaemia of one and four segments on thallium imaging and the third patient had normal coronary arteries, suggesting that there was no relation between arrhythmia and the severity of coronary disease.

\section{WALL MOTION BY MAGNETIC RESONANCE IMAGING}

The quality of the cine images before dipyridamole infusion was adequate for the analysis of wall motion in all patients but, as previously observed, ${ }^{9}$ the contrast between blood and the myocardium was better in the two short axis planes. The lower contrast in the long axis planes complicated the measurement of left ventricular volume particularly at end systole. Image quality was poorer in some patients after dipyridamole, especially in those in whom chest pain and tachypnoea developed, but in no case did this interfere with the interpretation of stress wall motion.

In all of the 23 patients with previous myocardial infarction, regional abnormalities of wall motion, wall thinning, or both were seen (fig 2). The site of these abnormalities accorded closely with the electrocardiogram, thallium201 myocardial perfusion imaging, and $x$-ray ventriculography. Wall motion was normal before dipyridamole in the patients without

Table 4 Induction of chest pain by dipyridamole as a predictor of the development of a new wall motion abnormality

\begin{tabular}{llc}
\hline & No chest pain & Chest pain \\
\hline No new wall motion abnormality & 11 & 5 \\
New wall motion abnormality & 2 & 22 \\
\hline$\chi^{2}=13.3 ; p<0.001$. &
\end{tabular}


Figure 2 Magnetic resonance and thallium201 images of infarction without reversible ischaemia. The magnetic images show ( $A$ and $B$ ) end diastolic and end systolic frames before the infusion of dipyridamole and $(C$ and $D)$ after the infusion of dipyridamole. The arrows in $B$ indicate an area of myocardium in the inferolateral wall that was thinned and did not contract normally. There was no change after dipyridamole stress $(D)$. The site accorded with the non-reversible defect in the stress (E) (arrowed) and redistribution ( $F$ ) thallium short axis tomogram. The patient had an occluded left circumflex artery with infarction.
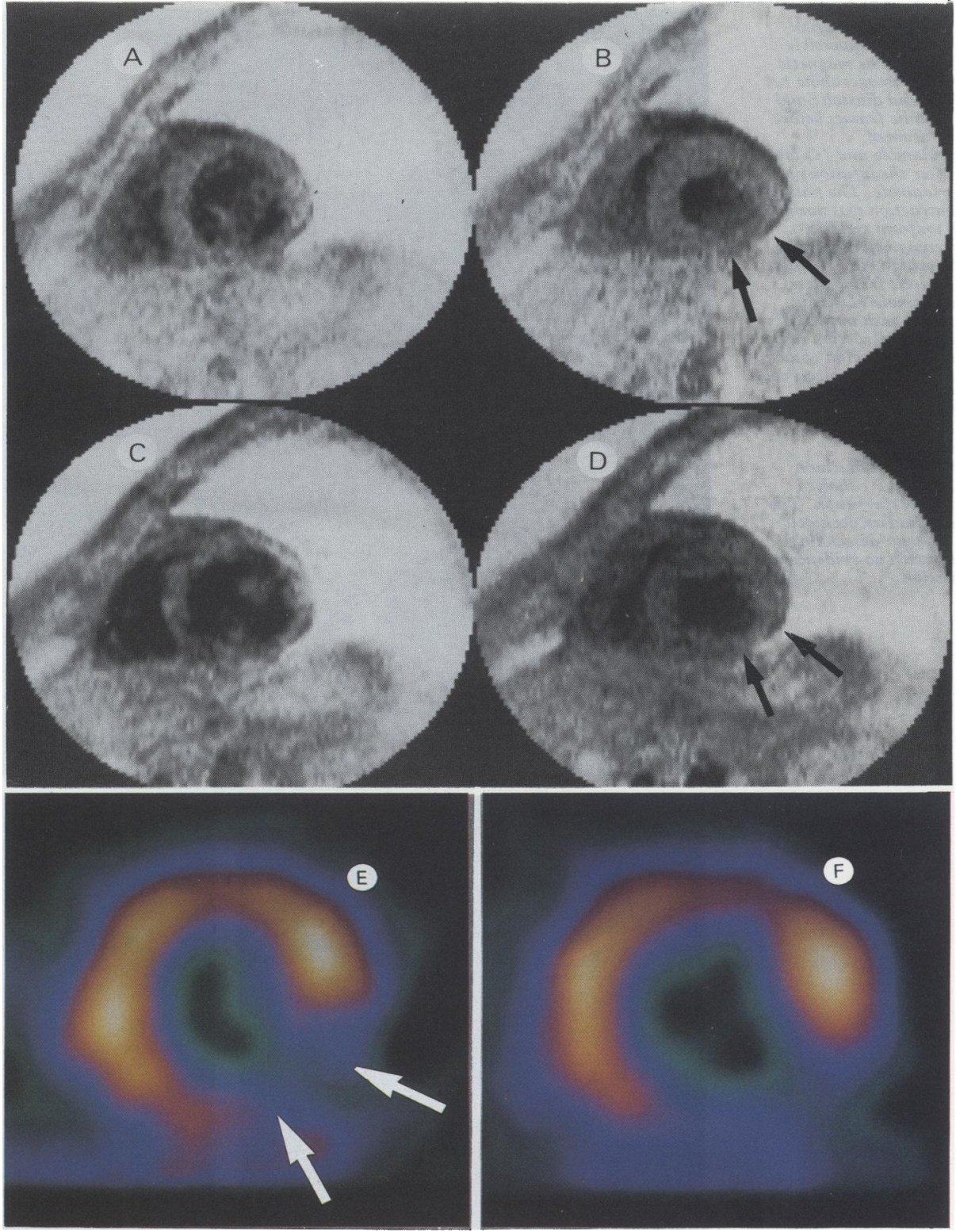

previous infarction, though there was some normal variation with apparent hypokinesis in the region of the membranous septum and some apical thinning and hypokinesis.

After infusion of dipyridamole wall motion deteriorated by at least one grade in at least one segment in $24(60 \%)$ patients (fig 3$)$. Of these, 10 had normal wall motion before dipyridamole but 14 patients did not. In these patients with previous infarction, the new abnormality occurred in a normal region in seven, in an already abnormal region in four (hypokinesis became akinesis), and in both normal and abnormal regions in three. The new wall motion abnormalities always occurred in the territory of an abnormal coronary artery and their site accorded closely with the site of a reversible thallium-201 defect, although the wall motion abnormality was often smaller. Of the 16 patients $(40 \%)$ without a wall motion abnormality induced by dipyridamole, nine had previous myocardial infarction with ab-

Table 5 Relation between the number of segments with reversible defects of thallium-201 uptake induced by dipyridamole and likelihood of a new wall motion abnormality

\begin{tabular}{lcc}
\hline & Negative $M R$ & Positive $M R$ \\
\hline 0-2 Segmental thallium defects & 16 & 8 \\
3-9 Segmental thallium defects & 0 & 16 \\
\hline$\chi^{2}=15 \cdot 1 ; \mathrm{p}<0.001$. &
\end{tabular}


Figure 3 Magnetic resonance and thallium201 images of reversible ischaemia. The magnetic resonance images show ( $A$ and $B$ ) end diastolic and end systolic frames before the infusion of

dipyridamole and $(C$ and $D$ ) after the infusion of dipyridamole. The pattern of contraction was normal

thickening before infusion of dipyridamole $(B)$. The end systolic frame after dipyridamole $(D)$ was abnormal with impaired extent of contraction in the anteroseptal region (black arrows). The site accorded with that on the stress thallium short axis tomogram $(E)$ (white arrows). The

redistribution thallium tomogram $(F)$ showed complete reperfusion. The patient had an occluded left anterior descending artery with no evidence of infarction. with uniform systolic
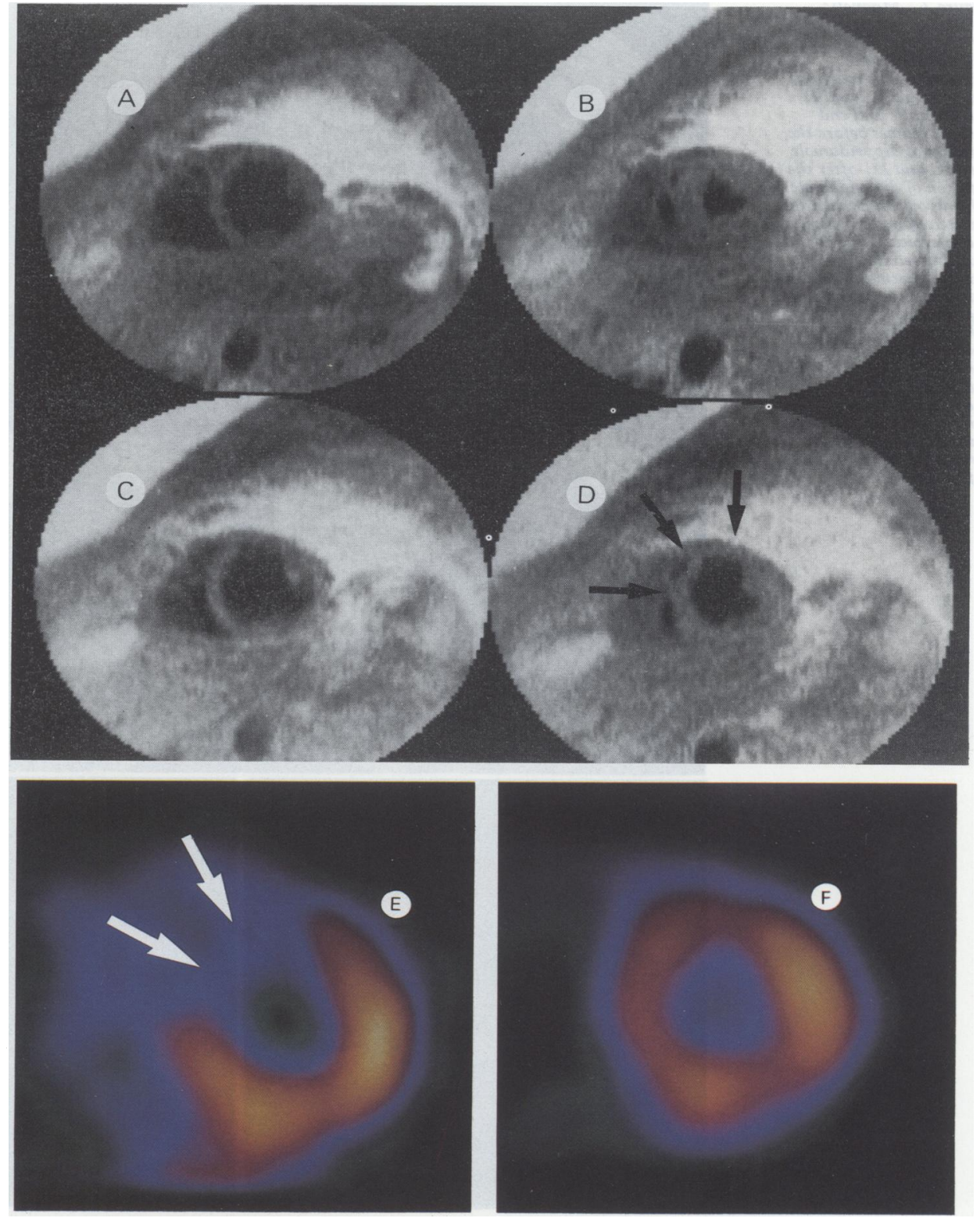

normal wall motion and seven had normal wall motion.

There was a strong relation between the

Table 6 Mean left ventricular volumes before and after dipyridamole in the groups of patients with (positive MRI) and without (negative MRI) wall motion abnormalities induced by the infusion

\begin{tabular}{lccc}
\hline & Before & After & Change (95\% CI) \\
\hline Positive MRI: & & & \\
$\quad$ End diastolic volume $(\mathrm{ml})$ & 146 & 138 & $-8(-20,+4)$ \\
End systolic volume $(\mathrm{ml})$ & 65 & 61 & $-4(-10,+2)$ \\
Stroke volume $(\mathrm{ml})$ & 81 & 77 & $-4(-15,+7)$ \\
Ejection fraction $(\%)$ & 57 & 58 & $+1(-3,+5)$ \\
Negative MRI: & & & $-2(-11,+8)$ \\
End diastolic volume $(\mathrm{ml})$ & 132 & 130 & $-5(-14,+4)$ \\
End systolic volume $(\mathrm{ml})$ & 52 & 47 & $+3(-9,+16)$ \\
Stroke volume $(\mathrm{ml})$ & 80 & 83 & $+3(-3,+9)$ \\
Ejection fraction $(\%)$ & 61 & 64 & \\
\hline
\end{tabular}

extent of coronary artery disease and the likelihood of a wall motion abnormality being induced by dipyridamole (table 3 ). Similarly, the development of chest pain after dipyridamole was a good predictor of the presence of a new wall motion abnormality (table 4). One of the two patients with a new wall motion abnormality but no chest pain had insulin dependent diabetes mellitus with a peripheral neuropathy.

\section{THALLIUM-201 MYOCARDIAL PERFUSION} IMAGING

Of the 23 patients with previous myocardial infarction, all had defects of thallium-201 uptake in the redistribution images, and 20 had additional reversible defects induced by dipy- 


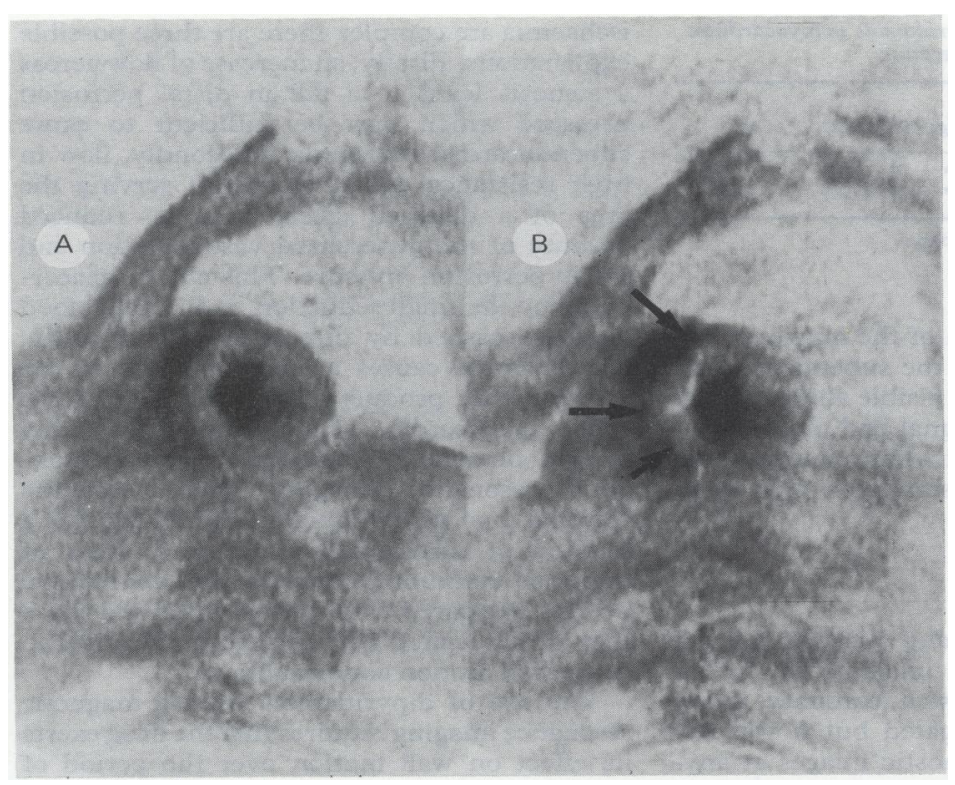

Figure 4 Magnetic resonance image with subendocardial signal change. The magnetic resonance images (reverse video format) show end systolic frames ( $A$ ) before and $(B)$ after dipyridamole. The cine display showed delayed septal contraction. A considerable decrease in the signal intensity of the septum was also visible which extended from the anterior wall to mid-septum (large black arrows) and continued down the inferior septum (small black arrow) apparently in the subendocardium. The stress thallium short axis tomogram (C) showed the corresponding extensive anterior, septal, and inferior. wall perfusion deficit (short white arrows) that became partially reperfused (D). It is likely that 24 hour delayed redistribution imaging would show further reperfusion in these segments. The patient had diseased left anterior descending and right coronary arteries.
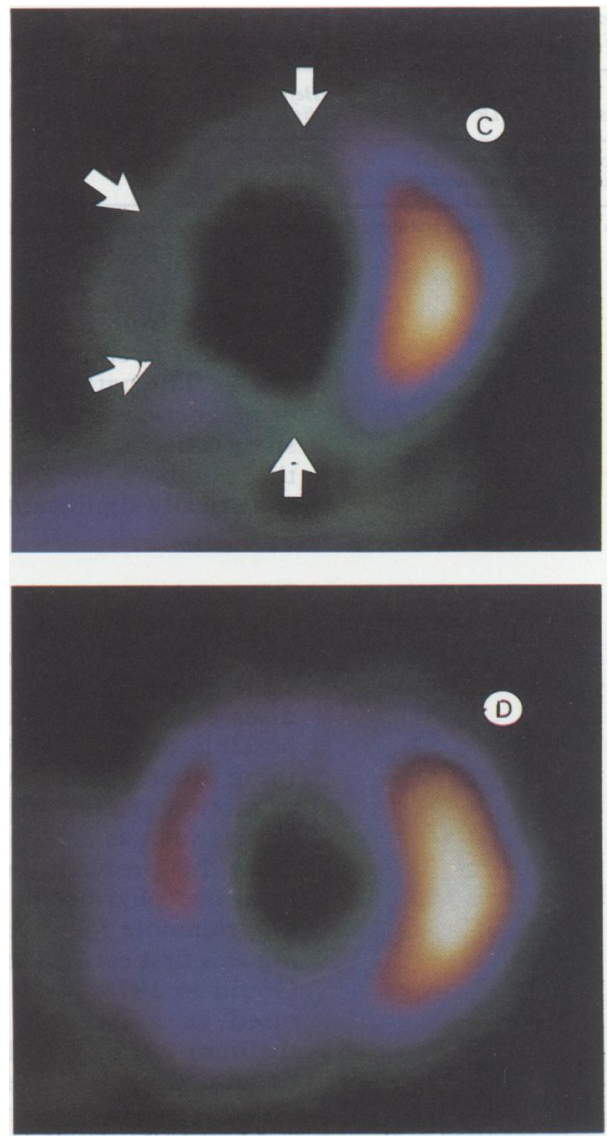

ridamole, of which 14 were new defects and six were a deterioration of a pre-existing abnormality. Of the 17 patients without previous infarction, all had normal redistribution images and 16 had new abnormalities induced by dipyridamole. The patient with a normal thallium-201 scan had normal coronary arteries.

There was a strong correlation between the number of reversible thallium-201 defects and the likelihood of a new wall motion abnormality seen by magnetic resonance (table 5 ). Defects larger than two segments were always associated with reversible wall motion abnormalities. Of the 16 negative magnetic resonance scans, 12 had reversible defects smaller than two segments, while only two of the positive magnetic resonance scans had perfusion defects smaller than two segments.

VENTRICULAR VOLUMES AND EJECTION FRACTION Table 6 shows the changes in end diastolic left ventricular volume, end systolic volume, stroke volume, and ejection fraction. There was no

Table 7 Mean change in magnetic resonance signal after dipyridamole in areas with reversible perfusion defects and normal myocardium

\begin{tabular}{lllll}
\hline Normalised MR signal & $\begin{array}{l}\text { Before } \\
\text { dipyridamole }\end{array}$ & $\begin{array}{l}\text { After } \\
\text { dipyridamole }\end{array}$ & Change $(95 \%$ CI) & $p$ \\
\hline $\begin{array}{l}\text { Reversible perfusion defect } \\
\text { Normal perfusion }\end{array}$ & 540 & 554 & $+14^{\star}(-27,+55)$ & NS \\
\hline
\end{tabular}

${ }^{\star} \mathrm{p}=\mathrm{NS}$. significant difference between the values before dipyridamole infusion in patients with new wall motion abnormalities or without, and though there was a trend towards a decrease in volumes after dipyridamole in both groups, covariance analysis showed no differences between groups.

MAGNETIC RESONANCE SIGNAL CHANGES IN THE MYOCARDIUM

The myocardial signal in the magnetic resonance images was normalised to alterations in signal from fat, to correct for changes arising from different acquisition variables before and after dipyridamole infusion (table 7 ). There was a small increase in signal after dipyridamole, both in the segments with normal perfusion and in those with reversible perfusion defects, but the changes were not statistically significant and there was no difference between these two groups. Not all of the segments with reversible perfusion defects had wall motion abnormalities, however, because after dipyridamole thallium defects can occur without ischaemia. There was a significant fall in signal in segments with new wall motion abnormality and an increase in signal in adjacent segments with normal wall motion $(p<0.05)$ (table 8 ). In nine of the 24 patients with new wall motion abnormalities, the abnormally low signal was 
Table 8 Mean change in magnetic resonance signal after dipyridamole in myocardium with a reversible wall motion abnormality and in normal myocardium

\begin{tabular}{lllll}
\hline Normalised MR signal & $\begin{array}{l}\text { Before } \\
\text { dipyridamole }\end{array}$ & $\begin{array}{l}\text { After } \\
\text { dipyridamole }\end{array}$ & Change $(95 \%$ CI) & $p$ \\
\hline Abnormal wall motion & 543 & 530 & $-13^{\star}(-2,-26)$ & $<0.05$ \\
Normal wall motion & 519 & 531 & $+12^{\star}(-7,+30)$ & NS \\
\hline
\end{tabular}

${ }^{*} p<0.05$. In nine patients the signal reduction was visible on the images.

apparent from inspection of the images and it was most pronounced in the subendocardium (fig 4). The patients with visible abnormalities of magnetic resonance signal had more extensive perfusion defects on thallium imaging, but the numbers were too small for this to be statistically significant.

\section{Discussion}

The possibility of combining dynamic exercise with magnetic resonance imaging for the investigation of patients with coronary artery disease has been investigated but it was not possible to acquire diagnostic images at anything other than submaximal exercise because of motion artefact. ${ }^{1}$ Very rapid imaging techniques such as echo planar imaging may overcome this problem, but an alternative strategy is to use pharmacological stress. The use of dipyridamole for myocardial perfusion imaging was first established in dog experiments by Gould in $1978^{10}$ and it has since been recognised as a method of inducing defects in thallium-201 images that is at least as reliable as dynamic exercise. The thallium-201 defects do not necessarily correspond with areas of ischaemia, but wall motion abnormalities have been demonstrated by echocardiography ${ }^{3}$ and by radionuclide ventriculography ${ }^{4}$ and it is reasonable to suppose that there is ischaemia in these cases. We performed the present study to establish the feasibility of dipyridamole magnetic resonance imaging for the investigation of such patients with coronary artery disease; and to investigate the relation between thallium201 defects induced by dipyridamole and wall motion abnormalities - a relation that has not previously been fully explored.

Dipyridamole acts at the level of the cardiac arteriolar myocyte, where it increases interstitial concentrations of adenosine by the combined effects of inhibition of the facilitated uptake of adenosine and inhibition of its breakdown by adenosine deaminase. Activation of the myocyte membrane purinoceptors leads to an increase of intracellular cyclic adenosine monophosphate and arteriolar vasodilatation. ${ }^{11}$ With Gould's original regimen $(0.56 \mathrm{mg} / \mathrm{kg}$ over 4 minutes $)^{10}$ the increase in coronary arterial flow in humans is variable, but it was reported to be between $250 \%{ }^{12}$ and $600 \% .^{13}$ The flow reserve is reduced in arteries with fixed stenoses, ${ }^{14}$ and the differential flow between territories served by normal and by stenosed arteries may be sufficient to produce an apparent defect of thallium-201 uptake. As we have confirmed, it is also possible to produce ischaemia in the territory of a stenosed artery, and though the mechanisms of this ischaemia are complex there are three possible explanations. Firstly, an increase of flow across a stenosis leads to a fall in distal perfusion pressure which may be sufficient to cause subendocardial ischaemia. ${ }^{10}$ Secondly, flow in high resistance collateral vessels serving the area of a diseased artery may be reduced because of the generalised vasodilatation and fall in perfusion pressure. This will be exacerbated by the small reduction in diastolic blood pressure caused by dipyridamole. ${ }^{15}$ Thirdly, dipyridamole causes a small increase in the rate-pressure product, mainly because of the reflex tachycardia, which raises myocardial oxygen demand. ${ }^{15}$ Techniques such as magnetic resonance imaging which examine regional myocardial function should provide a method of distinguishing between areas of impaired thallium-201 uptake that are relative defects compared with normal areas and those that are associated with sufficient ischaemia to cause wall motion abnormalities.

The use of dipyridamole during magnetic resonance imaging requires that the drug exerts its effect on wall motion over the period of imaging, which is approximately three minutes for a single acquisition but approximately 15 minutes for a complete stress study. Because there is no direct relation between the plasma concentration of dipyridamole and coronary flow we did not measure plasma dipyridamole during the acquisition. The relation between the action of dipyridamole on coronary flow and the consequent myocardial dysfunction is also unclear, but it is reasonable to suppose that the two occur together. Studies of coronary arterial flow in humans suggest that maximal flow occurs about $2 \frac{1}{2}$ minutes after the end of infusion $^{13}$ and that it continues at close to maximum for a further $9-14$ minutes ${ }^{16}$ with the half life for flow reduction of approximately 33 minutes. ${ }^{12}$ These figures differ from those found by Gould in the dog, where maximal flow increase was seen five minutes after the end of the four minute infusion with peak flow lasting for 3-5 minutes. ${ }^{10}$ In addition to the data reported on the time course of flow changes after intravenous dipyridamole it is known that after exercise stress regional wall motion changes persist for up to 20 minutes after the end of exercise. ${ }^{17} 18$ For constancy of effects on wall motion, therefore, we decided to administer a further $10 \mathrm{mg}$ bolus of dipyridamole at 10 minutes provided there were no contraindications.

With magnetic resonance imaging we showed reversible wall motion abnormalities after dipyridamole in $24(62 \%)$ of 39 patients with coronary artery disease and $24(67 \%)$ of 36 patients with reversible thallium defects. Studies with other imaging techniques have shown similar results though there is a wide variation in the reported sensitivity for coronary artery disease, varying from $13 \%{ }^{5}$ to $67 \%{ }^{4}$ for radionuclide ventriculography, and from $52 \%{ }^{19}$ to $89 \%{ }^{6}$ for echocardiography. This may be explained by several factors including the severity of disease in the population studied, ${ }^{19}$ the dosage of dipyridamole used, ${ }^{20}$ and improvements in imaging techniques. ${ }^{54}$ There 
was a close correlation between the site of the induced wall motion defect and the site of the thallium-201 perfusion defect in each patient and this is the first such observation made using equivalent tomographic techniques. A similar observation was made when echocardiography was compared with planar thallium201 imaging $^{21}$ though the differences between the two techniques mean that direct comparison is difficult. By using tomographic techniques we have also shown that the size of the thallium-201 defect is important. All patients without wall motion abnormalities induced by dipyridamole had thallium-201 defects affecting two or fewer segments, while only two patients with wall motion abnormalities had reversible thallium-201 defects affecting less than two segments. There was a similar relation with the number of diseased arteries, in that all patients with three vessel disease had new wall motion abnormalities induced by dipyridamole, while only two of nine patients with single vessel disease had new abnormalities.

We showed a strong relation between the occurrence of chest pain and the development of a wall motion abnormality. This was reported in some studies ${ }^{1922}$ but not in others ${ }^{20}{ }^{23}$ but it is likely that this relation is determined by the severity of disease. Because up to $74 \%$ of patients with coronary artery disease do not experience chest pain after dipyridamole infusion $^{23}$ and because adenosine is known to cause chest pain in the absence of disease, ${ }^{24}$ it seems unlikely that chest pain induced by dipyridamole will be a useful marker of the presence of disease, though it may be a marker of severe disease.

The changes in ventricular volumes and ejection fraction seen in our study are of limited clinical value because of the wide variation and the overlap between patients with and without new wall motion abnormality. In any event, the biplane area-length method that we used assumes that the ventricle is an ellipsoid of revolution and significant errors can be made if this is not the case. ${ }^{8}$ Unfortunately, it is more difficult to perform the accurate multislice method of measuring ventricular volume ${ }^{25}$ in the limited time available after dipyridamole infusion.

The reduction of magnetic resonance signal seen in nine $(41 \%)$ of the 22 patients with new wall motion abnormality suggests the possibility of using measurements of myocardial relaxation time to detect ischaemia. Many different factors influence the magnetic resonance signal but, unfortunately, it is unlikely that the observed changes were the results of alterations in relaxation times, because significant changes in $\mathrm{T} 2$ were not seen until an hour after experimental coronary occlusion. ${ }^{26}$ The altered motion of the abnormal segment might also explain changes in signal; however, hypokinesis would lead to a rise in signal rather than the observed fall. It is most likely that the changes were the result of alterations in the blood content of the myocardium, and this would be supported by the fact that the areas of signal loss were mainly subendocardial where the most severe ischaemia would be expected. Further studies using magnetic resonance contrast agents such as gadolinium diethylene- triamine pentaacetic acid may throw further light on these findings.

DJP is an Amersham research fellow. We are grateful to the Medical Research Council, Amersham International, CORDA and the National Heart and Chest Hospitals for financial support. We also thank Elisabeth Burman, Karl Lotey, and Majorie Watson for their help.

1 Schaefer S, Peshock RM, Parkey RW, Willerson JT. A new device for exercise MR imaging. Am J Roentgenol 1986; 147:1289-90.

2 Stratman HG, Kennedy HL. Evaluation of coronary artery disease in the patient unable to exercise: alternatives to exercise stress testing. Am Heart J 1989;1 17:1344-65.

3 Picano E. Dipyridamole echocardiography test: historical background and physiologic basis. Eur Heart $J 1989 ; 10$ : 365-76.

4 Cates CU, Kronenberg MW, Collins HW, Sandler MP. Dipyridamole radionuclide ventriculography: a test with high specificity for severe coronary artery disease. $\mathrm{J} \mathrm{Am}$ Coll Cardiol 1989;13:841-51.

5 Harris D, Taylor D, Condon B, Ackery D, Conway N. Myocardial imaging with dipyridamole: comparison of the Myocardial imaging with dipyridamole: comparison of the sensitivity and specificity of
MUGA. J Nucl Med 1982;7:1-5.

6 Josephson RA, Weiss JL, Flaherty JE, Ouyang P, Shapiro EP. Dipyridamole echocardiography detects vulnerable myocardium in the early post-infarction period [Abstract]. Circulation 1986;74(suppl II):469.

7 Bryant DJ, Payne JA, Firmin DN, Longmore DB. Measurement of flow with NMR imaging using a gradient pulse and phase difference technique. J Comput Assist Tomogr 1984;8:588-93.

8 Underwood SR, Gill CRW, Firmin DN, et al. Left ventricular volume measured rapidly by oblique magnetic tricular volume measured rapidly by oblique

9 Underwood SR, Burman ED, Firmin DN, et al. Cine MRI of ventricular function: optimal imaging parameters [Abstract]. Berkeley:

10 Gould KL. Noninvasive assessment of coronary stenoses by myocardial perfusion imaging during pharmacological coronary vasodilatation. 1 Physiologic basis and experimental validation. Am J Cardiol 1978;41:267-78.

11 Szegi J, Szentmiklosi AJ, Cseppento A. On the action of specific drugs influencing the adenosine induced activation of cardiac purinoceptors. In: Papp J Gy, ed. Cardiovascular pharmacology 1987: results, concepts and perspectives. Budapest: Akademiai Kiado, 1987:591-9.

12 Brown BG, Josephsen MA, Petersen RB, et al. Intravenous dipyridamole combined with isometric handgrip for near maximal acute increase in coronary flow in patients with maximal acute increase in coronary flow in patients with

13 Wilson RF, Laughlin DE, Ackell PH, et al. Transluminal, subselective measurement of coronary artery blood flow velocity and vasodilator reserve in man. Circulation 1985; 72:82-92.

14 Feldman RL, Nichols WW, Pepine CJ, Conti CR. Acute effects of intravenous dipyridamole on regional coronary haemodynamics and metabolism. Circulation 1981;64: 333-44.

15 Chambers CE, Brown KA. Dipyridamole induced ST segment depression during thallium-201 imaging in patients with coronary artery disease: angiographic and 37-41.

16 Harris DNF. The use of dipyridamole with myocardial imaging. Bristol University, 1982. MD thesis.

17 Roging. WS, Feigenbaum H, Armstrong WF, Dillon JC, O'Donnell J, McHenry PW. Exercise echocardiography: a clinically practical addition in the evaluation of coronary artery disease. J Am Coll Cardiol 1983;2:1085-91.

18 Homans DC, Sublett E, Dai X, Bache RJ. Persistence of regional left ventricular dysfunction after exercise induced myocardial ischaemia. $J$ Clin Invest 1986;77:66-73.

19 Margonato A, Chierchia S, Cianflone D, et al. Limitations of dipyridamole echocardiography in effort angina pectoris Am J Cardiol 1987;59:225-30.

20 Picano E, Lattanzi F, Masini M, Distante A, L'Abbate A. High dose dipyridamole echocardiography test in effort angina pectoris. J Am Coll Cardiol 1986;8:848-54.

21 Ferrara $\mathrm{N}$, Bonaduce $\mathrm{D}$, Leosco $\mathrm{D}$, et al. Two dimensional echocardiographic evaluation of ventricular asynergy: induced by dipyridamole: correlation with thallium scaninduced by dipyridamole: correlation

22 Tauchert M, Behrenbreck DW, Hotzel J, Hilger HH. Ein Tauchert M, Behrenbreck DW, Hotzel J, Hilger HH. Ein arinsuffienz. Dtsch Med Wochenschr 1976;101:35-7.

$23 \mathrm{Zhu}$ YY, Lee W, Botvinick E, et al. The clinical and pathophysiologic implications of pain, ST abnormalities and scintigraphic changes induced during dipyridamole infusion: their relationships to the peripheral haemodynamic response. Am Heart $J$ 1988;116:1071-80.

24 Sylven C, Beerman B, Jonzon B, Brandt R. Angina pectorislike pain provoked by intravenous adenosine in healthy volunteers. Br Med J 1986;293:227-30.

25 Longmore DB, Klipstein RH, Underwood SR, et al. Dimensional accuracy of magnetic resonance in studies of Dimensional accuracy of magnet.

26 Pflugfelder PW, Wisenberg G, Prato FS, Turner KL, Carroll SE. Serial imaging of canine myocardial infarction
by in vivo nuclear magnetic resonance. $\mathrm{J} \mathrm{Am}$ Coll Cardiol by in vivo nuclea
$1986 ; 7: 843-9$. 